\title{
Pediatric heart transplantation: Year in review 2020
}

\author{
Shriprassad Deshpande, MBBS, MS, ${ }^{a}$ Joshua D. Sparks, MD, ${ }^{b}$ and Bahaaldin Alsoufi, MD $^{c}$
}

The year 2020 saw some important publications in the field of pediatric heart transplantation (PHT). Several focused on increasing donor utilization and expanding the donor pool. We are learning more about various factors that impact early and long-term morbidities in these patients. Numerous articles explored noninvasive methods of diagnosis of rejection, which is particularly relevant to this population. In this review, we summarize these recent publications.

\section{DONOR UTILIZATION AND WAITLIST MORTALITY}

A large number of publications in 2020 focused on persistent waitlist mortality and suboptimal donor organ use in PHT. Denfield and colleagues ${ }^{1}$ reviewed the literature and noted that waitlist mortality remains high and varies between countries and among centers within the United States, with infants and those with complex congenital heart disease remaining at highest risk. Kirk and colleagues ${ }^{2}$ published the first International Society for Heart and Lung Transplantation (ISHLT) consensus statement on donor selection in PHT. Again they noted that waitlist mortality remains high (17\%-30\%) and varies among centers and between counties (eg, United States, 17\%; Japan, 30\%). The statement offered a consensus regarding the effects of donor factors on outcomes and provided some recommendations based on the best available evidence. The authors identified biases that impact donor acceptance and noted that those biases are predictable by behavioral economics and decision making psychology. ${ }^{2}$ This decision making psychology was further discussed by Butler and colleagues, ${ }^{3}$ who examined such considerations basing PHT program evaluation on transplantation rather than on waitlist successes (ie, transplantation mortality after accepting a marginal donor is more carefully scrutinized than waitlist mortality after rejecting such a donor), and how outcome scrutiny and previous donor rejections by others might create risk aversion and influence donor acceptance. Giafaglione and associates ${ }^{4}$ validated these points in their review

\footnotetext{
From the a'Department of Cardiology and Cardiac Critical Care, Children's National Hospital, Washington, DC and Departments of ${ }^{\mathrm{b}}$ Pediatrics and ${ }^{\mathrm{c}}$ Cardiovascular and Thoracic Surgery, University of Louisville School of Medicine, Norton Children's Hospital, Louisville, Ky.

Received for publication April 18, 2021; revisions received April 18, 2021; accepted for publication April 19, 2021; available ahead of print May 3, 2021.

Address for reprints: Bahaaldin Alsoufi, MD, Department of Cardiovascular and Thoracic Surgery, University of Louisville School of Medicine, Norton Children's Hospital, 201 Abraham Flexner Way, Suite 1200, Louisville, KY 40202 (E-mail: balsoufi@hotmail.com).

J Thorac Cardiovasc Surg 2021;162:418-21

0022-5223/\$36.00

Copyright (c) 2021 by The American Association for Thoracic Surgery https://doi.org/10.1016/j.jtcvs.2021.04.073
}

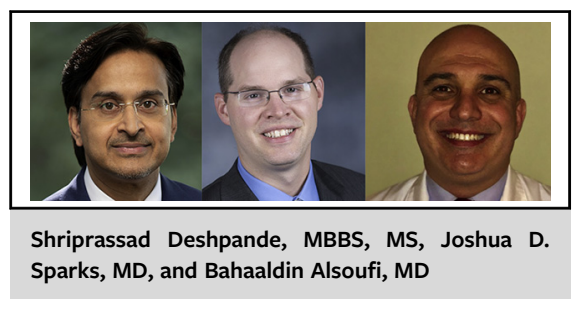

\begin{abstract}
CENTRAL MESSAGE
Publications in 2020 focused on optimizing donor utilization, increasing the donor pool, and tackling modifiable risk factors.
\end{abstract}

of the United Network for Organ Sharing/Organ Procurement and Transplantation Network (UNOS/OPTN) data. They noted that donor heart refusal decreased with time (from $37 \%$ to $23 \%$ ), but $80 \%$ were still rejected for poor quality. The refusal rate varied among programs, with only $47 \%$ of hearts labeled poor quality by multiple programs. This suggested a lack of consensus among centers in decision making and donor acceptance criteria. Butts and colleagues ${ }^{5}$ showed that programs with a higher donor refusal rate had a higher waitlist mortality and lower rate of transplantation after listing without improved posttransplantation mortality, and subsequently higher 1-year mortality after listing. Programs are more likely to accept marginal donors for the sickest patients and that might contribute to worse transplantation outcomes with these donors. Riggs and associates ${ }^{6}$ compared low and high-risk donor cohorts after propensity matching on recipient characteristics. When these characteristics were harmonized, post-transplant survival didn't significantly differ between low and high-risk donors. They suggested a bigger role for accepting "high-risk donor." Similarly, Das and colleagues ${ }^{7}$ analyzed the UNOS data and demonstrated that the use of donors with low ejection fraction $(<50 \%)$ or prolonged ischemic time ( $>4$ hours) resulted in outcomes similar to those with standard donors but with shorter waitlist times. They assessed the interaction between donor and recipient risk factors and showed that recipient's risk category had far greater impact on outcomes compared with these donor factors.

Baez Hernandez and colleagues ${ }^{8}$ presented their singlecenter experience of standardization of donor selection to reduce practice variability. They saw significant reductions 
in their waitlist time and the number of refused donors after implementation of such a data-driven practice. Importantly, there was no impact on early post-transplantation outcomes. Finally, the practice of organ oversizing in adults with congenital heart disease could have negative implications by increasing waitlist time and mortality. Clark and associates $^{9}$ analyzed the UNOS data to explore this issue. They showed that graft oversizing did not result in improved survival compared with size-matched donors, but sex mismatch, pretransplantation renal dysfunction, and longer ischemic times were associated with higher mortality, possibly warranting a change in donor decision making.

\section{IMPROVING PHT OUTCOMES}

Given the donor shortage and increased scrutiny of transplantation results, a number of studies looked at outcome predictors and ways to improve survival. Riggs and colleagues ${ }^{10}$ analyzed the UNOS data and assessed pretransplantation factors that affected survival. They examined modifiable risk factors (mechanical ventilation, renal and hepatic dysfunction) in addition to nonmodifiable risk factors (infant age, congenital heart disease). They found that adding modifiable risk factors incrementally decreased 1year survival following transplantation; for example, 1year survival was $95 \%$ in infants with congenital heart disease without any of the aforementioned modifiable factors and decreased to $58 \%$ in those on ventilator and with kidney dysfunction. The authors argued for the use of such information to properly counsel families and provide realistic expectations and, more importantly, to optimize these children and make timely decisions about listing. Some of them may be at too high risk for transplantation. Mechanical circulatory support, although challenging in children, might help to optimize these patients and make them better candidates for transplantation. Another study by Riggs and associates $^{11}$ examined outcomes in children who received mechanical circulatory support before PHT with the aim of identifying the optimal duration of support that would result in improved organ function (eg, mechanical ventilation need, renal dysfunction) and consequently 1-year survival following PHT. Although the optimal timing differed based on clinical situation and type of mechanical support type, allowing adequate time for organ recovery and patient rehabilitation before listing seemed to offer survival advantage. These findings are important while efforts are made to optimize the children's condition while awaiting PHT and maximizing survival as well.

The use of ABO-incompatible (ABOi) transplantation in infants has increased. Decreasing waitlist time could potentially decrease morbidity and mortality before PHT and consequently lead to improved post-transplantation survival. Kozik and colleagues ${ }^{12}$ analyzed the UNOS data with a focus on children listed as ABOi and demonstrated a significant increase in listing of $\mathrm{ABO}$ and transplantation of ABOi hearts with time. Overall, $54 \%$ of children age $<2$ years were listed as ABOi. In the recent era, nearly $25 \%$ of these received an incompatible organ. Importantly, ABOi PHT did not affect early or long-term survival or the incidence of rejection and led to a significant decrease in waitlist time for blood group $\mathrm{O}$ recipients. These observations were further validated by Urschel and colleagues ${ }^{13}$ using the Pediatric Heart Transplant Society registry. These authors also demonstrated that children initially listed for compatible transplantation and changed to ABOi had higher 1-year mortality, which likely reflects precarious clinical status, worsening clinical condition, and need for extracorporeal membrane oxygenation. Avoidance of this might be achieved by early listing as ABOi.

\section{MISCELLANEOUS TOPICS RELATED TO PHT}

Various topics in PHT were explored in 2020. Shaw and colleagues ${ }^{14}$ evaluated the use of various preservation solutions in donor harvest and found that the University of Wisconsin solution was the most commonly used solution $(40 \%)$, but there was a significant variation in practice in general. They found no relationship between the type of preservation solution and 30-day or 1-year mortality.

Spinner and associates ${ }^{15}$ used the Pediatric Health Information System data to study the impact of tracheostomy on PHT outcomes. They found that pretransplant tracheostomy during the same hospitalization as well as post-transplant tracheostomy were both associated with significant inhospital mortality. Understanding the need for tracheostomy in this group could potentially unearth modifiable factors leading to improved survival.

Stephens and associates ${ }^{16}$ studied normalization of hemodynamics after PHT. They demonstrated a significant delay in normalization of hemodynamics after PHT in children with a history of Glenn and Fontan procedures compared with those with dilated cardiomyopathy. Although $85 \%$ of children with dilated cardiomyopathy had normalized hemodynamics by 6 months posttransplantation, only $28 \%$ of Fontan and $44 \%$ of Glenn patients demonstrated such normalization. Although this did not impact survival or retransplantation, we know that this represents potential morbidity. More research is needed into modifiable factors, such as collateral burden in the single ventricle population, along with other factors, such as pulmonary vascular resistance and recipient-donor sizing practices.

There is continued interest in the development of noninvasive biomarkers for monitoring of PHT patients with various efforts underway. One such report, by Richmond and colleagues, ${ }^{17}$ evaluated the utility of donor fraction cell free DNA (dd cfDNA) and showed that in a representative population of pediatric and adult heart transplant recipients, dd cfDNA served as an excellent screening tool for rejection with a negative predictive value $>90 \%$ for any 
rejection. Such tests may fundamentally change the use of surveillance biopsies in heart transplant care. In addition, total cfDNA levels may have utility in this population. Scott and colleagues ${ }^{18}$ showed that a total cfDNA level $>50 \mathrm{ng} /$ $\mathrm{mL}$ was predictive of increased mortality (hazard ratio, 32.9) and had a significant association with infection.

Continued expansion of PHT to newer regions is exciting. Garekar and colleagues ${ }^{19}$ provided insight into management and outcomes of PHT in resource-limited settings. They reported excellent early $(100 \%)$ and short-term $(85 \%)$ survival with comparable patient profiles.

Finally, in an interesting analysis of attitudes, Padilla and colleagues ${ }^{20}$ surveyed congenital heart surgeons and cardiologists regarding their attitudes toward xenotransplantation in the current era. Although the general acceptance was high (80\%-88\%), a significant reduction in acceptance was seen if the xenotransplantation was to be used as a bridge to human transplantation or as primary intervention for hypoplastic left heart syndrome. Continued research investment in alternatives to human donors, such as tissue engineering and xenotransplantation, will be needed if the increasing demands for pediatric heart transplantation are to be met.

\section{Conflict of Interest Statement}

The authors reported no conflicts of interest.

The Journal policy requires editors and reviewers to disclose conflicts of interest and to decline handling or reviewing manuscripts for which they may have a conflict of interest. The editors and reviewers of this article have no conflicts of interest.

\section{References}

1. Denfield SW, Azeka E, Das B, Garcia-Guereta L, Irving C, Kemna M, et al. Pediatric cardiac waitlist mortality—still too high. Pediatr Transplant. 2020;24: e13671.

2. Kirk R, Dipchand AI, Davies RR, Miera O, Chapman G, Conway J, et al. ISHLT consensus statement on donor organ acceptability and management in pediatric heart transplantation. J Heart Lung Transplant. 2020;39:331-41.

3. Butler A, Chapman G, Johnson JN, Amodeo A, Böhmer J, Camino M, et al. Behavioral economics - a framework for donor organ decision-making in pediatric heart transplantation. Pediatr Transplant. 2020;24:e13655.

4. Giafaglione J, Morrison A, Gowda C, Gajarski R, Nandi D. Pediatric donor heart allocation in the United States, 2006-2017: current patterns and potential for improvement. Pediatr Transplant. 2020;24:e13743.
5. Butts RJ, Baez Hernandez N, Kirk R, Bano M, Davies R. Center donor refusal rate is associated with worse outcomes after listing in pediatric heart transplantation. Transplantation. November 9, 2020 [Epub ahead of print].

6. Riggs KW, Kroslowitz BJ, Chin C, Zafar F, Morales DLS. Pondering higherrisk pediatric heart donors: can we use more? Ann Thorac Surg. 2020;110: 198-205.

7. Das B, Trivedi JR, Sinha P, Ramakrishnan K, Alsoufi B, Deshpande SR. Interplay between donor and recipient factors impacts outcomes after pediatric heart transplantation: an analysis from the United Network for Organ Sharing database. Pediatr Transplant. 2021;25:e13912.

8. Baez Hernandez N, Kirk R, Davies R, Bano M, Sutcliffe D, Pirolli T, et al. A comprehensive strategy in donor acceptance: impact on pediatric waitlist and heart transplant outcomes. Pediatr Transplant. 2020;24:e13764.

9. Clark DE, Byrne RD, Mazurek JA, Opotowsky AR, Schlendorf KH, Xu M, et al. Sizing heart transplant donors in adults with congenital heart disease. J Thorac Cardiovasc Surg. February 28, 2020 [Epub ahead of print].

10. Riggs KW, Zafar F, Lorts A, Chin C, Bryant R III, Tweddell JS, et al. The reality of limping to pediatric heart transplantation. J Thorac Cardiovasc Surg. 2020; 159:2418-25.e1.

11. Riggs KW, Zafar F, Lorts A, Villa CR, Bryant R III, Morales DLS. Optimizing postcardiac transplantation outcomes in children with ventricular assist devices: how long should the bridge be? ASAIO J. 2020;66:787-95.

12. Kozik D, Sparks J, Trivedi J, Slaughter MS, Austin E, Alsoufi B, et al. ABOincompatible heart transplant in infants: a UNOS database review. Ann Thorac Surg. September 7, 2020 [Epub ahead of print].

13. Urschel S, McCoy M, Cantor RS, Koehl DA, Zukerman WA, Dipchand AI, et al. A current era analysis of ABO-incompatible listing practice and impact on outcomes in young children requiring heart transplantation. $J$ Heart Lung Transplant. 2020;39:627-35.

14. Shaw TB, Lirette S, Carter KT, Kutcher ME, Baran DA, Copeland JG, et al. Does pediatric heart transplant survival differ with various cardiac preservation solutions? Clin Transplant. 2020;34:e14122.

15. Spinner JA, Denfield SW, Puri K, Morris SA, Costello JM, Moffett BM, et al. Hospital outcomes for pediatric heart transplant recipients undergoing tracheostomy: a multi-institutional analysis. Pediatr Trans plant. 2021;25: e13904.

16. Stephens EH, Tannous P, Mongé MC, Eltayeb O, Devlin PJ, Backer CI, et al. Normalization of hemodynamics is delayed in patients with a single ventricle after pediatric heart transplantation. J Thorac Cardiovasc Surg. 2020;159: 1986-96.

17. Richmond ME, Zangwill SD, Kindel SJ, Deshpande SR, Schroder JN, Bichell DP, et al. Donor fraction cell-free DNA and rejection in adult and pediatric heart transplantation. J Heart Lung Transplant. 2020;39:454-63.

18. Scott JP, Ragalie WS, Stamm KD, Mahnke DK, Liang HL, Simpson PM, et al. Total cell-free DNA predicts death and infection following pediatric and adult heart transplantation. Ann Thorac Surg. October 8, 2020 [Epub ahead of print].

19. Garekar S, Meeren T, Patel V, Patil S, Dhanke S, Mali S, et al. Early experience with pediatric cardiac transplantation in a limited resource setting. Ann Pediatr Cardiol. 2020;13:220-6.

20. Padilla LA, Rhodes S, Sorabella RA, Hurst DJ, Cleveland DC, Dabal RJ, et al. Attitudes toward xenotransplantation: a survey of parents and pediatric cardiac providers. Pediatr Transplant. 2021;25:e13851.

Key Words: heart transplantation, mechanical circulatory support 


\section{Pediatric Heart Transplantation: Recent Articles From AATS Journals}
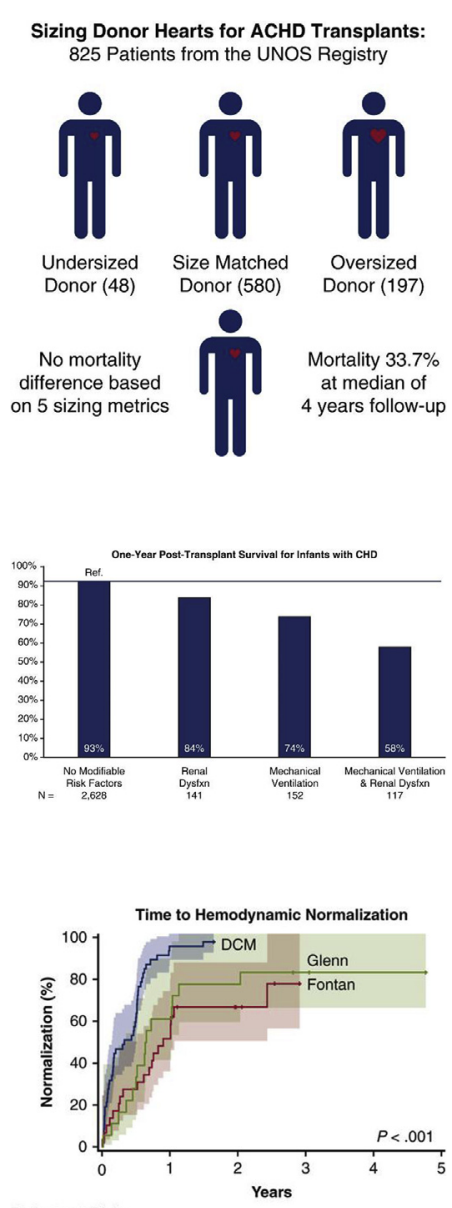

Patients-at-Risk - DCM 47 - Fontan 29
- Glenn 18
JTCVS: Sizing heart transplant donors in adults with congenital heart disease. Clark $D E$, Byrne RD, Mazurek JA, Opotowsky AR, Schlendorf KH, Xu M, Zalawadiya S, Menachem JN. J Thorac Cardiovasc Surg. 2021 [In Press].

Commentary: One size fits all, maybe. Jawitz OK, Raman V. J Thorac Cardiovasc Surg. 2021 [In Press].

Commentary: Accepting only over-sized donors for adult congenital heart disease-Is it being overcautious? Shudo Y, Maeda K. J Thorac Cardiovasc Surg. 2021 [In press.]

JTCVS: The reality of limping to pediatric heart transplantation. Riggs $K W$, Zafar F, Lorts A, Chin C, Bryant R 3rd, Tweddell JS, Morales DLS. J Thorac Cardiovasc Surg. 2020;159(6):24182425 .

Commentary: Crawling toward heart transplantation and beyond. Deshpande $S R$, Yerebakan C. J Thorac Cardiovasc Surg. 2020;159(6):2426-2427.

Commentary: Providing a "leg up" for those who "limp" to heart transplantation. John MM, Wilder TJ, Blackstone EH. J Thorac Cardiovasc Surg. 2020;159(6):2427-2428.

Commentary: Pediatric heart transplantation-Seeing the forest for the trees. Bradley SM. J Thorac Cardiovasc Surg. 2020;159(6):2429-2430.

JTCVS: Normalization of hemodynamics is delayed in patients with a single ventricle after pediatric heart transplantation. Stephens EH, Tannous P, Mongé MC, Eltayeb O, Devlin PJ, Backer CL,et al. J Thorac Cardiovasc Surg. 2020;159(5):1986-1996.

Commentary: How long until a new heart is a "normal" heart in transplanted single-ventricle patients? Hernandez NB, Davies RR. J Thorac Cardiovasc Surg. 2020;159(5):1997-1998.

Commentary: It isn't easy being single. Purifoy E, Adachi I. J Thorac Cardiovasc Surg. 2020; 159(5):1999-2000,

Commentary: The environment matters: The effects of passive circulation are not quickly reversed by a change of heart. Thangappan K, Morales DLS. J Thorac Cardiovasc Surg. 2020; 159(5):2001-2002.

Commentary: The mechanics, semantics, and "echonomics" of myocardial recovery on pediatric ventricular assist device therapy. Woods RK. J Thorac Cardiovasc Surg. 2021 [In Press.] 